\title{
Fatal Parasitic Gastroenteritis and Pneumonia In A Captive African Civet (Civettictis civetta)
}

\author{
Adam $\mathrm{M}^{1^{*}}$., Akanbi B. O' ${ }^{1}$, Atata J. A ${ }^{1}$, Shoyinka S.V.O' ${ }^{2}$ and Ambali S.f. \\ ${ }^{1}$ Department of Veterinary Pathology, Faculty of Veterinary Medicine, University of Ilorin, Ilorin, Nigeria \\ ${ }^{3}$ Department of Veterinary Pathology and Microbiology, Faculty of Veterinary Medicine, University of Nigeria, Nsukka, Nigeria \\ ${ }^{3}$ Department of Veterinary Pharmacology and Toxicology, Faculty of Veterinary Medicine, University of Ilorin, Ilorin, Nigeria
}

Accepted December 2019, and Published December, 2019

\begin{abstract}
The African civet cat (Civetticus civetta) is native to Ethiopia, Guinea, Senegal, and other places in equatorial Africa. Civet cats are grouped under order Carnivora and family Viverridae and are wild viverids of the tropics. They are nocturnal and solitary animals that only mix during mating. Though, civet cats are primarily carnivorous, they are opportunistic omnivores, but feeds on a mixture of fruits and vegetables, maize meal and meat (1 kg/civet), eggs, insects, rodents, invertebrates and birds. Parasitic and infectious diseases have become a major concern in the conservation of endangered species as they can cause mortality, dramatic population declines, and even contribute to local extinction events. This report concern is about a Civet which was acquired in May, 2016 by the private forest garden. It showed no previous sign of illness prior to its death in July. The carcass weighed approximately $4 \mathrm{~kg}$ and was in good bodily condition. Congestion of the lungs were evident, while the stomach was empty, but the duodenum contained cream-coloured mucoid exudates admixed with two long cestodes, measuring up to $52 \mathrm{~cm}$ and numerous short segments of this worm, (up to $2 \mathrm{~cm}$ in length) within the lumen of the proximal $1 / 3^{\text {rd }}$ of the duodenum and extending to the jejunum and ileum. Parasitological examination revealed that the cestodes was Dipylidium spp. It was concluded that, the Civet could have died as a result of parasitic gastroenteritis and pneumonia 53 days after it was introduced into the forest garden. It is most likely that the infection was acquired from the wild before the animal was introduced into the forest garden.
\end{abstract}

Key words: Civet cat, Dipylidium caninum, congestion, gastroenteritis, pneumonia.

Corresponding Author:

email: abumaryamasabe@gmail.com

Tel.: +234 (0)803 5233719 


\section{INTRODUCTION}

Captive animals are prone to diseases as a result of different intrinsic and extrinsic factors [16]. Helminthosis among other diseases can lead to mortality [14]. Several intestinal helminthes species such as trematodes, cestodes and nematodes have been reported in these animals. Civets are grouped under order Carnivora and family Viverridae [10]. The African civet (Civetticus civetta) is native to Ethiopia, Guinea, Senegal, and other places in equatorial Africa $[5,10]$.The African Civet is renowned for its perineal gland secretion known as 'civet' or 'civet musk' commercially used as a basic fixative ingredient in perfume industry. Exportation of the African civet is a major foreign exchange earner for Ethiopia and Zanzibar [4]. Civet cats are carnivorous [5] and opportunistic omnivores [13]. In captivity they are often fed on mixture of fruit and vegetables, maize meal and meat (about $1 \mathrm{~kg} /$ Civet) or four eggs every five days [10]. They also feed on insects, rodents, invertebrates and birds [3, 13]. Its age at sexual maturity is between 6 months and 1year. The gestation length is 65 to 75 days with a maximum of 4 kits per litter [7], even though [13] reported a kit size of 3 to 5 per litter. The females are polyestrous and are able to have 2 or 3 litters a year. The average lifespan of the African civet is 15 to 20 years.

Parasitic and infectious diseases have become the major concerns in conservation of endangered species [12] as they can lead to mortality, dramatic population declines, and even contribute to local extinction events [11].

\section{Case description:}

This female African civet cat was acquired on $18^{\text {th }}$ May, 2016. There was no physical sign of illness prior to death. However, there was heavy down pour of rain on the night of its death that is, on $10 / 11^{\text {th }}$ July, 2016 (some 53 days after its acquisition). A comprehensive post-mortem examination was carried out. Tissue samples of liver, kidney, intestine, lungs were collected, fixed in 10\% neutral buffered formalin for 24 hours and processed for routine histopathology using standard procedure. Helminths worm harvested from the gastrointestinal tract were sent to parasitology laboratory for identification.

\section{Gross Lesions:}

Grossly, the slightly pale carcass was emaciated and in fair body condition, and was free of ectoparasites. The right and left apical lobes of the lungs were severely congested. The stomach was empty but the duodenum contained creamcoloured mucoid exudates. There were two adult cestode worms of about $30 \mathrm{~cm}$ and $32 \mathrm{~cm}$ long respectively found within the lumen of the proximal one-third of the duodenum, extending to the jejunum and ileum (fig. 1). Also, numerous, short round segments, $2-7 \mathrm{~mm}$ in length, were present within the lumen of the distal one-third of the duodenum. The urinary bladder was distended, but patent.

\section{Histopathology:}

In the lung, numerous alveoli in the cranial lobe were filled with amorphous eosinophilic material (alveolar eodema), homogeneous eosinophilic fibrinous material (fibrin) and infiltrated with numerous neutrophils, macrophages and lymphocytic cells (fig. 2). Similar exudation extended into the tertiary and terminal bronchioles in a multifocal pattern. Here, the exudates contained debris of necrotic epithelia cells, indicating bronchiolitis. These desquamated epithelial cells occasionally occlude the airway lumen (Bronchiolitis). The ciliated columnar epithelium of the bronchioles were necrotized and infiltrated with numerous neutrophils, macrophages and lymhoplasmacytic cells (fig. 3). The lumina in some of the bronchioles were still patent. Many alveolar spaces were moderately distended (alveolar emphysema). 

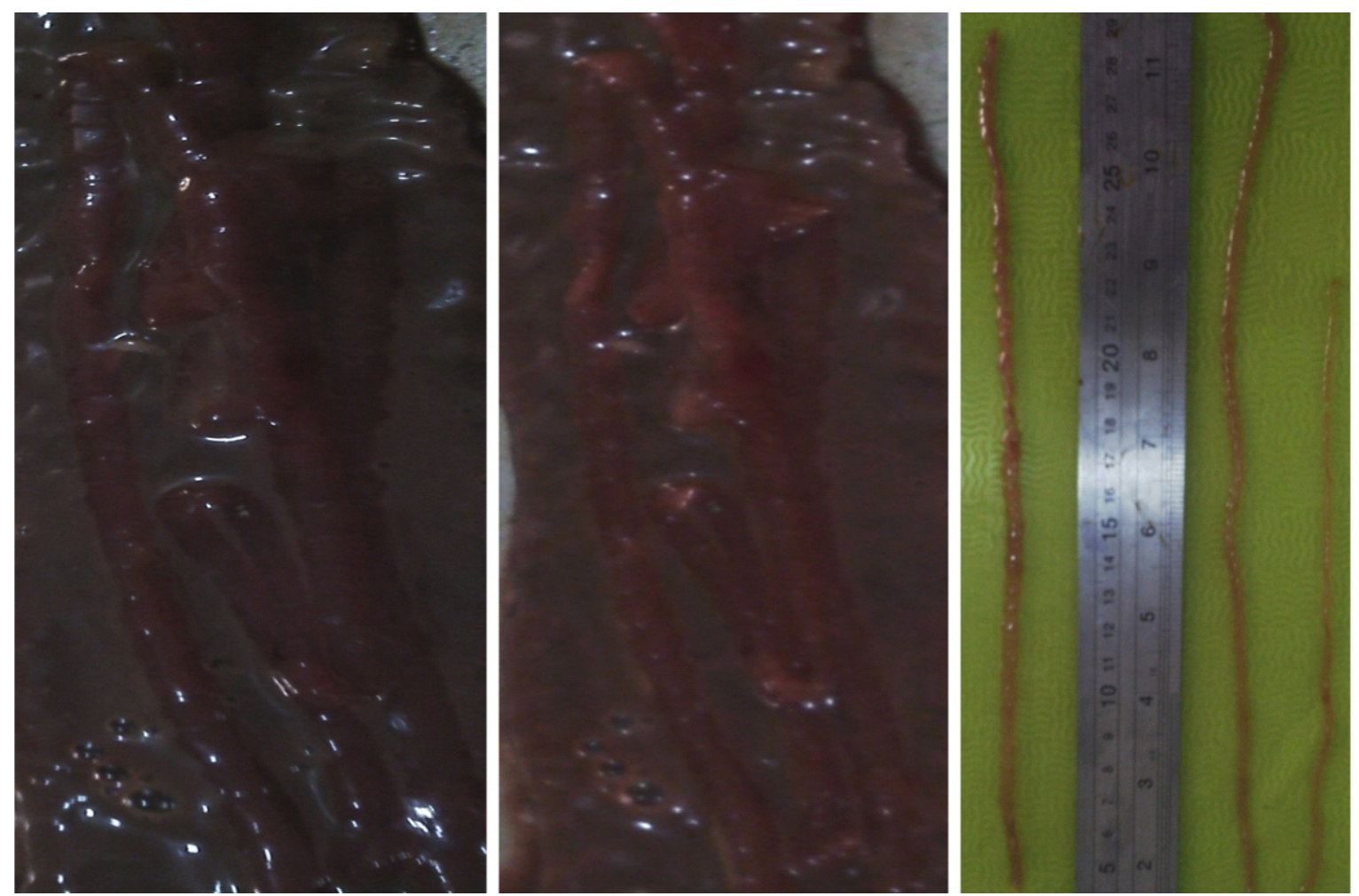

Figure 1: Showing the adult worms admixed in intestine.

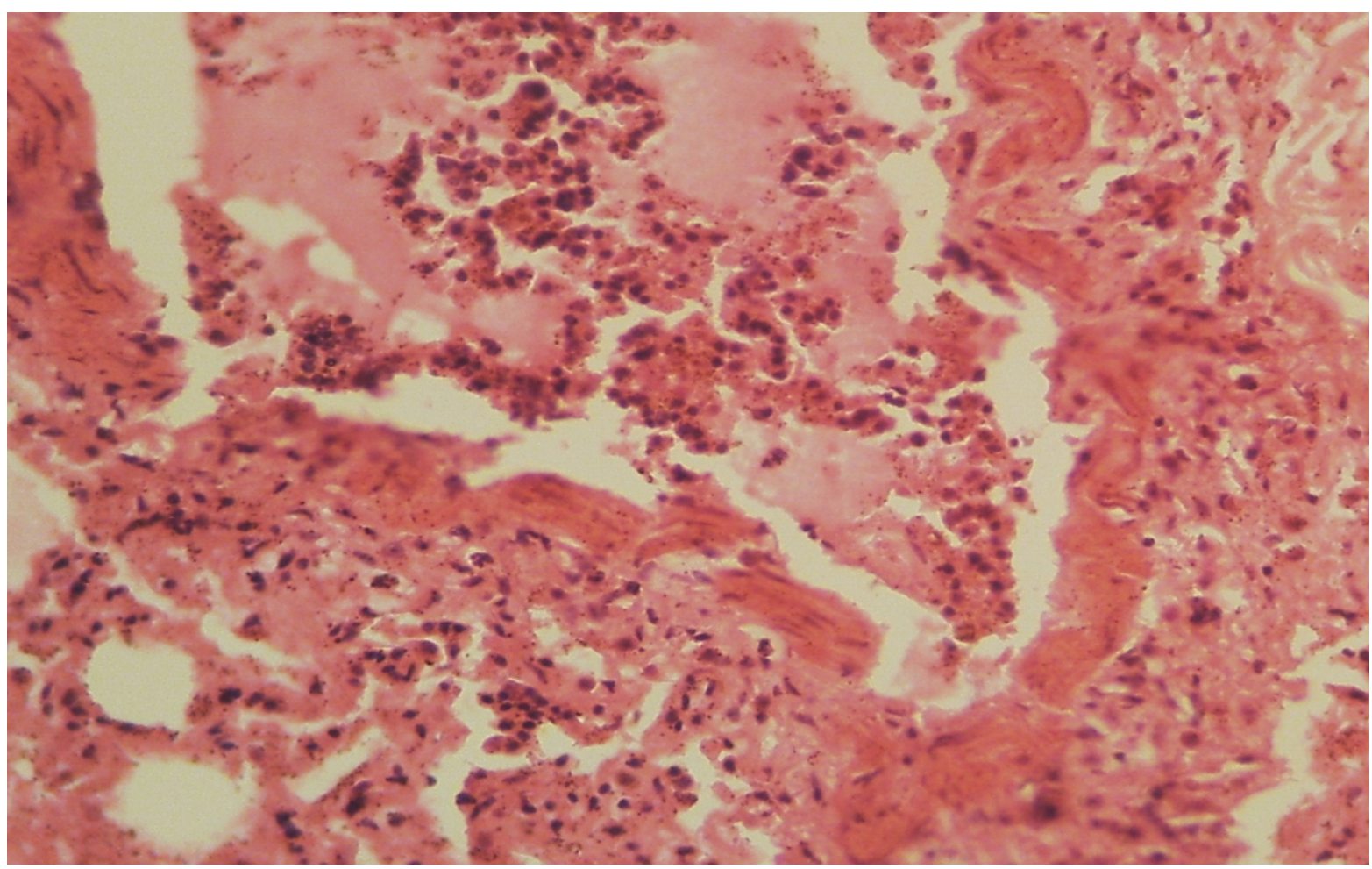

Figure 2: Showing broncho -pneumonia with intraluminal necrotised and desquamated columnar epithelial cells alveolar filled with oedema fluid and infiltration of neutrophi ls, macrophages and lymphocytic cells. H \& E stain x 400 . 


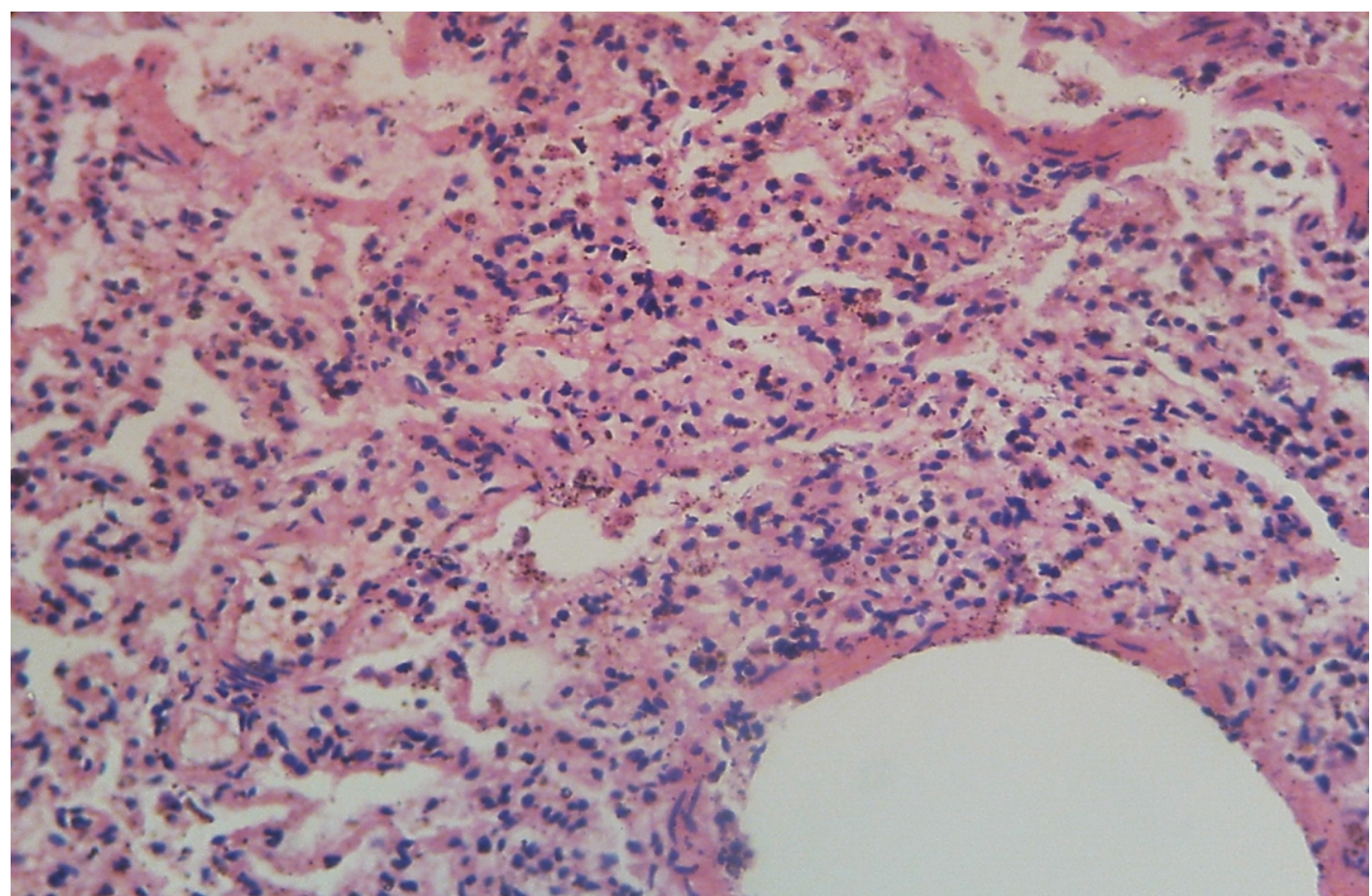

Figure 3: Showing broncho-alveolar pneumonia with infiltration of neutrophils, macrophages and lymphocytic cells. $\mathrm{H} \& \mathrm{E}$ stain $\mathrm{x} 400$.

DISCUSSION: The present study showed adult cestode worms (Dipylidium caninum) in the small intestine of the civet cat which indicates that wild animals are equally susceptible to fatal obvious helminth infection despite natural tolerance of most. Dipylidium caninum, also known as the "flea tapeworm, double-pore tapeworm or cucumber tapeworm" in reference to the shape of its cucumber-seedlike proglottids, resemble grains of rice or sesame seeds. It is a cyclophyllid cestode that infects organisms afflicted with fleas and canine chewing lice, including dogs, cats. It has been reported [8] that, helminth infection is more common than protozoa infection in animals in captivity with nematode eggs observed in $90 \%$ affected animals in captivity while protozoan were observed in only $38 \%$ animals [9]. Similar finding had been reported [6]. It has also been reported by [8] that helminthes infection is more prevalent than protozoa infection in Italian zoo. It has been observed that confinement of wild animals in zoological garden makes them more prone to different infections, especially helminth infections which have been found to be more common than other parasitic infections in wild and captive zoo animals. Nematode parasites have a direct life cycle and their transmission by feco-oral route through contaminated feed, water, and soil and have the potential to accumulate in a captive environment despite proper attention to feeding, watering, and maintenance of hygiene in captivity. Although, bacterial pathogens must have been responsible for the broncho-alveolar pneumonia, which however complicated the outcome of the case. Parasitic diseases are considered a major problem in zoo animals because of the increase environmental pollution due as a result of poor maintenance of animals in confined areas [15]. In wild conditions, animals have some natural resistance against parasitic diseases coupled with a state of balance between the parasite and the host and it rarely leads to harmful condition 
unless stressed [9]. In captivity wild animals parasitic infections are due to environmental changes in the living conditions and space limitations [3]. Captivity predisposes animals more to infections as the immune system of these zoo animals becomes low [9]. Alveoli oedema may occur as a result of aberrant changes in the hydrostatic and oncotic pressure acting across the micro-vessel walls. Alterations in the molecular structures that complicate the problem of fluid and solute passage in the endothelial wall which manifest as changes in hydraulic conductivity and the osmotic reflection coefficient for plasma proteins, or alterations in the lymphatic outflow system.

The bronchio - alveolar exudation suggests a descending infection of which the alveolar oedema fluid is an exudates. This, no doubt interfered with gaseous exchange and related mortality activities, such as vacuolar degeneration of the hepatocytes. The paleness of the carcass which tended to suggest that the animal was anaemic, which might be nutritional due to the parasitic effect of the worms in the small intestine [6].

In conclusion, the Civet died 53 days after post introduction to the forest garden. It is most likely that the infection was acquired from the wild before the animal was introduced into the forest garden. It is therefore imperative that animals from the wild be quarantined and subjected to through clinical examination before being introduced into the garden. There is also need for regular clinical examination of the animal in captivity generally. This way, mortality resulting from simple disease condition such as helminthosis can be prevented.

\section{REFERENCES}

1. Abebe, Y. D. (2003). Sustainable Utilization of the African Civet (Civettictis civetta) in Ethiopia. Second Pan-African symposium on the sustainable use of natural resources in Africa. Bihini Wonwa Musiti, IUCN, Gland, Switzerland and Cambridge, U.K.pp. 197-208.

2. Aguirre, A. A. Keefe, T. J. Reif, J. S. Kashinsky, L. Yochem, P. K. Saliki, J. T. Stott, J. L. Dubey, J. P. Goldstein, T. Braun, R. and Antonelis, G. (2007). Infectious disease monitoring of the endangered Hawaiian monk seal. Journal of Wildlife Disease, 43: 229241.

3. Beate, D. S (2000). Food and Agriculture Organization of the United Nations. World Watch List for Domestic Animal Diversity, third edition. FAO, Rome, Italy. Pp 702-703.

4. Bekele, T. A few ork, B. and Balakrishnan, M. (2008). Scentmarking by the African Civet Civettictis civetta in the Menagesha- Suba State Forest, Ethiopia. Small Carnivore Conservation, 38: 29-33.

5. Dannenfeldt, K. H. (1985). Europe Discovers Civet Cats and Civet. Journal of the History of Biology, 18(3): 403431.

6. Fagiolini, M. Riccardo, P. L. Piero, L. Paolo, C. Riccardo, V. and Stefania, P. (2010). Gastrointestinal parasites in mammals of two Italian zoological gardens. Journal of Zoo and Wild Medicine, 41(4): 662-670.

7. Kumera, W. (2005). Improving Civet cat farming for quality musk production (Amharic version). Agriculture and Rural Development Bulletin, 2 (6): 31 34. 
8. Lim, Y. A. Ngui, L. R. Shukri, J. Rohela, M.and Naim, H. R. M. (2008). Intestinal parasites in various animals at a zoo in Malaysia. Veterinary Parasitology, 157: 154-159.

9. Mir, A. Q. Dua, K. Singla, L. D. Sharma, S. and Singh, M. P. (2016). Prevalence of parasitic infection in captive wild animals in Bir Moti Bagh mini zoo (Deer Park), Patiala, Punjab Veterinary World, 9(6): 540-543.

10. Shalu, T. (2000). "Civettictis civetta", Animal Diversity Web. Accessed http://animaldiversity.ummz.umich.edu/si te/accounts/information/Civettictis civett a.htl.

11. Smith, K. F. Sax, D. F. and Lafferty, K. D. (2006). Evidence for the role of infectious disease in species extinction and endangerment. Conservation of Biology, 20: 1349-1357.

12. Smith, K. F. Acevedo, W. K. and Pedersen, A. B. (2009). The role of infectious diseases in biological conservation. Animal of Conservation, 12: 1-12.
13. Tolosa, T. and Regassa, F. (2007). The husbandry, welfare and health of captive African civets (Vivera civetica) in western Ethiopia. Animal Welfare, 16: 15-19.

14. Vicente, J. Palomares, F. Ruiz de Ibañe, R. and Ortiz, V. (2004). Epidemiology of Ancylostoma spp. in the endangered Iberian lynx (Lynx pardinus) in the Donana National Park, South-West Spain. Journal of Helminthology, 78: 179-183.

15. Wisely, S. M. Howard, J. Williams, S. A. Bain, O. Santymire, R. M. Bardsley, K. D. and Williams, E. S. (2008). An unidentified filarial species and its impact on fitness in wild populations of the black-footed ferret (Mustela nigripes). Journal of Wildlife Disease, $44: 53-64$.

16. Yavuz, S. S. Ertan, O. Hamza, A. and Serdar, A. (2014). Diagnostic Exercise: Gastroenteritis and Pneumonia Due to Mesocestoides spp. and Toxascaris leonina in a Eurasian Lynx (Lynx lynx). Pakistan Veterinary Journal, 34 (1): 143-145. 